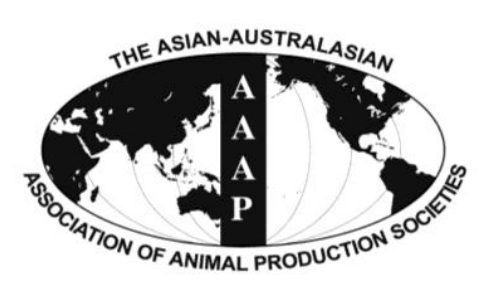

\title{
Effects of Dietary Supplementation with Ferulic Acid or Vitamin E Individually or in Combination on Meat Quality and Antioxidant Capacity of Finishing Pigs
}

\author{
Y. J. Li ${ }^{\text {a }}$ L. Y. Li ${ }^{\text {a }}$, J. L. Li, L. Zhang, F. Ga**, and G. H. Zhou \\ College of Animal Science and Technology, Synergetic Innovation Center of Food Safety and Nutrition, \\ Nanjing Agricultural University, Nanjing 210095, China
}

\begin{abstract}
This study aimed to evaluate the effects of vitamin E (VE), ferulic acid (FA) and their combination supplementation on meat quality and antioxidant capacities of finishing pigs. Sixty barrows were randomly allocated to four experimental diets using a $2 \times 2$ factorial arrangement with 2 VE supplemental levels $(0$ or $400 \mathrm{mg} / \mathrm{kg})$ and 2 FA supplemental levels $(0$ or $100 \mathrm{mg} / \mathrm{kg})$ in basal diets. After 28 days, six pigs per treatment were slaughtered. The results showed that VE supplementation increased loin eye area of pigs $(\mathrm{p}<0.05)$ and FA supplementation increased $\mathrm{pH}_{45 \mathrm{~min}}$ value $(\mathrm{p}<0.05)$. The interaction of $\mathrm{FA} \times \mathrm{VE}$ was observed in shear force of longissimus dorsi muscle ( $\mathrm{p}<0.05)$. Moreover, supplementation with VE decreased hepatic and sarcous malondialdehyde (MDA) content, increased hepatic glutathione (GSH) content and sarcous glutathione peroxidase (GSH-Px) activity ( $<<0.05)$. Additionally, supplementation with FA increased hepatic GSH-Px activity and decreased sarcous MDA content ( $\mathrm{p}<0.05)$. However, dietary treatment did not affect the expression of genes related to nuclear factor, erythroid 2-like 2 (NFE2L2) pathway. These results suggest that dietary FA and VE could partially improve meat quality and antioxidant capacity of finishing pigs, but not by activating NFE2L2 pathway under the normal conditions of farming. (Key Words: Ferulic Acid, Vitamin E, Meat Quality, Antioxidant Capacity, Nuclear Factor Erythroid 2-like 2-Antioxidant Response Element [NFE2L2-ARE])
\end{abstract}

\section{INTRODUCTION}

Oxidative stress is an imbalance between the production of reactive oxygen species (ROS) and the redox homeostasis of the body. Excessive ROS result in damage to biomolecules including lipid, protein, amino acids, and DNA (Fang et al., 2002). The removal of ROS is achieved by the antioxidant system including enzymatic reaction (e.g., superoxide dismutase [SOD], catalase, and glutathione peroxidases [GSH-Px]) and non-enzymatic reaction (e.g., glutathione [GSH], vitamins and polyphenols) (Fang et al., 2002). Generally, several ROS including malondialdehyde (MDA), protein carbonyls, aldehydes, ketones, and

\footnotetext{
* Corresponding Author: Feng Gao. Tel: +86-25-84399007, Fax: +86-25-84395314, E-mail: gaofeng0629@sina.com

${ }^{a}$ Yanjiao Li and Liyun Li contributed equally to this work.

Submitted Jun. 12, 2014; Revised Aug. 27, 2014; Accepted Oct. 16, 2014
}

phenolic compounds are known to contribute to suboptimal pork quality (Ma et al., 2010a). For modern pig production, oxidative stress induced by endogenous and exogenous factors causes the oxidation of lipid, protein and metal ions easily to generate these ROS and result in bad pork quality.

Previous studies have demonstrated that dietary supplementation with antioxidants including vitamin $\mathrm{E}$ (VE), vitamin $\mathrm{C}$, selenium, flavonoid and natural plant extracts had positive effects on meat quality through control ROS balance effectively (Corino et al., 2003; Kuhn et al., 2004; Descalzo and Sancho, 2008; Ma et al., 2010a), among which, dietary VE has been widely used in antioxidant for improving meat quality. In addition, ferulic acid (FA) is a natural antioxidant which belongs to the phenolic compounds, largely present in fruits, vegetables, cereals and herbs (Balasubashini et al., 2003). In clinical application, FA has been reported to exert potential health benefits like anti-inflammatory, antiatherogenic, antidiabetic, antiageing, 
neuroprotective, radioprotective and hepatoprotective, all these benefits attribute to its strong antioxidant activity (Srinivasan et al., 2007). However, there is limited information related to the effects of dietary FA or combination of FA and VE on antioxidant capacity in meat system.

Nuclear factor, erythroid 2-like 2 (NFE2L2) pathway is regarded as one of the most important pathways in the cell to prevent cells from damage caused by oxidative stress (Copple et al., 2008). Under normal conditions, NFE2L2 is sequestered in the cytoplasm by interacts with the actinanchored protein kelch-like ECH-associated protein 1 (KEAPl), and upon recognition of chemical signals imparted by ROS or electrophilic molecules, NFE2L2 dissociates from $K E A P 1$, translates to the nucleus, binds to antioxidant response element (ARE), and transactivates phase II genes and antioxidant genes (Kensler et al., 2007). Besides the direct antioxidant activity of VE and FA, they or their metabolites may also serve as indirect antioxidants by enhancing the cell's antioxidant system by activating NFE2L2 (Ma et al., 2010b; Li et al., 2012). However, to our knowledge, limited information is available about the effects of dietary FA and VE on the expression of genes related to NFE2L2 pathway. Moreover, whether there is any interaction between FA and VE in their antioxidant capacity in finishing pigs is still unclear. Therefore, the present study aimed to evaluate the effects of dietary supplementation with FA, VE, and their combination on meat quality, antioxidant capacities, the mRNA expression of genes related to nuclear factor, erythroid 2-like 2-antioxidant response element (NFE2L2-ARE) pathway in liver and muscle of finishing pigs.

\section{MATERIALS AND METHODS}

\section{Animals and diets}

A total of 60 barrows (Duroc $\times$ LandracexYorkshire, DLY) pigs were randomly allotted to four treatment diets using a $2 \times 2$ factorial arrangement with $2 \mathrm{VE}$ supplemental levels ( 0 or $400 \mathrm{mg} / \mathrm{kg}$ ) and 2 FA supplemental levels ( 0 or $100 \mathrm{mg} / \mathrm{kg}$ ) in basal diets. The basal diet was based on corn and soybean meal which met nutrient requirements of National Research Council (1998) for finishing pigs. The composition and nutrient level of the experimental diets were shown in Table 1. Each treatment consisted of three replicates (pens) with five pigs each and the initial body weights of pigs were approximately $75 \mathrm{~kg}$. All the pigs had free access to water and feed during this period. All pigs were housed in Furun pig farm, Anhui province, China. The experimental design and procedures were approved by the Animal Care and Use Committee of Nanjing Agricultural University.
Table 1. The composition and nutrient level of the basal diet

\begin{tabular}{lc}
\hline Items & \\
\hline Ingredients (g/kg) & 720 \\
Maize & 200 \\
Soybean meal & 40 \\
Wheat bran & 14 \\
Dicalcium phosphate & 10.5 \\
Limestone & 2 \\
Lysine-HCl & 3.5 \\
Salt & 10 \\
Premix ${ }^{1}$ & 1000 \\
Total & \\
Calculated nutrient levels & 13.91 \\
Digestible energy (MJ/kg) & 15.81 \\
Crude protein $(\%)$ & 0.88 \\
Calcium $(\%)$ & 0.57 \\
Total phosphorus (\%) & 0.98 \\
Lysine $(\%)$ & 0.50 \\
Methionine (\%)+cystine (\%) & 0.58 \\
Threonine (\%) & 0.18 \\
Tryptophan $(\%)$ &
\end{tabular}

${ }^{1}$ The premix provided per kilogram of diet: $100 \mathrm{mg}$ of iron as iron sulfate, $100 \mathrm{mg}$ of zinc as zinc oxide, $30 \mathrm{mg}$ of manganese as manganous oxide, $10 \mathrm{mg}$ of copper as copper sulfate, $0.3 \mathrm{mg}$ of selenium as sodium selenite, $0.5 \mathrm{mg}$ of iodine as calcium iodate, $2,758 \mu \mathrm{g}$ retinyl acetate, 25 $\mu \mathrm{g}$ cholecalciferol, $20 \mathrm{mg}$ DL- $\alpha$-tocopheryl acetate, $3.0 \mathrm{mg}$ menadione sodium bisulphite, $2.0 \mathrm{mg}$ thiamin mononitrate, $6.0 \mathrm{mg}$ riboflavin, 3.0 $\mathrm{mg}$ pyridoxine hydrochloride, $20 \mathrm{mg}$ nicotinic acid, $8 \mathrm{mg}$ calcium pantothenate, $0.5 \mathrm{mg}$ folic acid, $30 \mu \mathrm{g}$ cyanocobalamin, $300 \mathrm{mg}$ choline.

\section{Slaughtering, carcass traits and sample collecting}

After 28 days, 6 pigs with 2 pigs per pen were randomly selected after $12 \mathrm{~h}$ fasting and transported to the commercial abattoir. Pigs were slaughtered by electrical stunning and exsanguinations. They were then scalded, depilated, labeled, eviscerated, divided into halves. Hot carcass weight was directly recorded on the assembly and then sent to the chilling room $\left(4^{\circ} \mathrm{C}\right)$. In the chilling room, the back fat depth was measured at the first rib, last rib and last lumbar vertebra and their average values was taken as back fat depth. The loin eye area of longissimus dorsi (LD) was traced over the exposed surface muscle area between the 12th and 13th ribs using sulphate papers, and then the area was measured using a planimeter according to the method of DeVol et al. (1988). The lean percentage was calculated by a mathematical model $y=57.742-$ $0.5871 \times x 1+0.2023 \times \times 2$ (x1 represents back fat thickness of last lumbar vertebra, $\mathrm{x} 2$ stands for the distance from the end of gluteus medius to the edge of spinal cord tube) described by Li et al. (2006). For the evaluation of meat quality, LD chops trimmed of extramuscular fat and connective tissue were stored at $4^{\circ} \mathrm{C}$. Moreover, within 45 min postmortem, samples of LD muscles from the left carcass side and liver were immediately frozen in liquid nitrogen and stored at 
$-20^{\circ} \mathrm{C}$ until analysis of antioxidant indices or stored at $-80^{\circ} \mathrm{C}$ for relative gene expression analysis.

\section{Meat quality measurements}

Muscle $\mathrm{pH}$ at $45 \mathrm{~min}\left(\mathrm{pH}_{45 \min }\right)$ and $24 \mathrm{~h}$ (ultimate $\mathrm{pH}$, $\mathrm{pH}_{\mathrm{u}}$ ) postmortem were measured using a portable and waterproof $\mathrm{pH}$ meter (HI9125, Hanna Instruments, ClujNapoca, Romania). Meat colour (lightness, L*; redness, a*; yellowness, $\mathrm{b}^{*}$ ) was measured at $24 \mathrm{~h}$ postmortem from a freshly cut surface using a chromameter CR-400 (Konica Minolta, Sensing Inc., Osaka, Japan) calibrated by a white plate before measurement. Drip loss was determined at $24 \mathrm{~h}$ postmortem. Briefly, approximately $30 \mathrm{~g}$ of cuboid LD sample trimmed of fat, was weighted and suspended in polyethylene plastic bag, ensured that sample does not make contact with bag. After $24 \mathrm{~h}$ at $4^{\circ} \mathrm{C}$, the samples were reweighed to calculate drip loss percentage as described by Honikel (1998). After measured the drip loss at $48 \mathrm{~h}$ postmortem, the meat samples were weighted and pack into boilable bags. Subsequently, the samples were cooked in a $75^{\circ} \mathrm{C}$ water bath to reach an internal temperature of $70^{\circ} \mathrm{C}$ as monitored using thermocouples. The cooked samples were then cooled in running water to room temperature, used for shear force value test using a shear apparatus (C-LM3B, Engineering College of Northeast Agricultural University, Harbin, China) with a load cell of $15 \mathrm{~kg}$ and a crosshead speed of $200 \mathrm{~mm} / \mathrm{min}$. Three meat strips $(1 \mathrm{~cm} \times 1 \mathrm{~cm} \times 3 \mathrm{~cm})$ from each sample were cut parallel to longitudinal axis of the muscle fibers to measure and calculate average shear force value. Shear force value was expressed in Newton (N).

\section{Muscle and liver antioxidant capacity analysis}

For biochemical assays, $0.5 \mathrm{~g}$ frozen LD muscle and liver samples were ice bath homogenized in $4.5 \mathrm{~mL}$ ice-cold physiological saline for $1 \mathrm{~min}$ and then centrifuged $(2,700 \mathrm{~g}$, $\left.4^{\circ} \mathrm{C}, 10 \mathrm{~min}\right)$. The supernatants were then subjected to the measurements of the activity of GSH-Px and the contents of GSH and MDA. The concentrations of total protein in liver and LD muscle were determined by TP kit (Nanjing Jiancheng Bioengineering Institute, Nangjing, China) according to the instructions of the manufacturer. All of those antioxidant indices in liver and LD muscle were determined by commercial GSH-Px, GSH and MDA kits (Nanjing Jiancheng Bioengineering Institute), and were normalized by total protein concentration in liver and LD muscle respectively according to the instructions of the manufacturer.

\section{RNA extraction and real-time quantitative polymerase chain reaction}

Total RNA was extracted from frozen LD muscle and liver samples using Trizol (Invitrogen, Carlsbad, CA, USA) according to the manufacturer's protocol. The purity and quantity of total RNA was measured by a NanoDrop 1000 spectrophotometer (Thermo Scientific, Wilmington, DE, USA) at 260 and $280 \mathrm{~nm}$. The RNA was treated with DNase I (Takara Biotechnology Co. Ltd., Dalian, China) to remove DNA and reverse transcribed to cDNA $(10 \mu \mathrm{L}$ reaction system for maximum use of $500 \mathrm{ng}$ of total RNA) using a PrimeScript RT Master Mix kit (Takara Biotechnology Co. Ltd., China) following the instructions.

Real-time polymerase chain reaction (PCR) was performed using ABI 7500 Real-Time PCR System (Applied Biosystems, Foster City, CA, USA) and SYBR Premix Ex Taq Kit (Takara Biotechnology Co. Ltd., China). Primers used for real-time quantitative PCR are presented in Table 2. The amplification was performed in a total volume of $20 \mu \mathrm{L}$, containing $10 \mu \mathrm{L}$ of SYBR Premix Ex Taq, 0.4 $\mu \mathrm{L}$ of each primer $(10 \mu \mathrm{M}), 0.4 \mu \mathrm{L}$ of ROX Reference Dye II, $2 \mu \mathrm{L}$ of cDNA and $6.8 \mu \mathrm{L}$ of sterilized doubled-distilled water. The real-time PCR program was as follows: $95^{\circ} \mathrm{C}$ for $30 \mathrm{~s}$, followed by 40 cycles of $95^{\circ} \mathrm{C}$ for $5 \mathrm{~s}, 58^{\circ} \mathrm{C}$ for $31 \mathrm{~s}$ and $70^{\circ} \mathrm{C}$ for $30 \mathrm{~s}$, and collected the fluorescence signal at $58^{\circ} \mathrm{C}$. Each sample was performed in triplicate. After amplification, melt curve analysis was performed to validate the specificity of the reactions. Relative gene

Table 2. Real-time quantitative PCR primers for NFE2L2-ARE related genes and $\beta$-actin of the finishing pigs

\begin{tabular}{|c|c|c|c|c|}
\hline Gene & Primer sequence (5' to $3^{\prime}$ ) & $\begin{array}{c}\text { Product } \\
\text { length (bp) }\end{array}$ & $\begin{array}{c}\text { Annealing } \\
\text { temperature }\left({ }^{\circ} \mathrm{C}\right)\end{array}$ & GenBank accession no. \\
\hline \multirow[t]{2}{*}{$\beta$-actin } & Forward: ATGGTGGGTATGGGTCAGAA & 122 & 58 & U07786 \\
\hline & Reversed: TTCTCCATGTCGTCCCAGTT & & & \\
\hline \multirow[t]{2}{*}{ GPX1 } & Forward: AGCCCAACTTCATGCTCTTC & 159 & 58 & NM_214201.1 \\
\hline & Reversed: CATTGCGACACACTGGAGAC & & & \\
\hline \multirow[t]{2}{*}{$G C L C$} & Forward: CAAACCATCCTACCCTTTGG & 172 & 58 & XM_003128335.4 \\
\hline & Reversed: ATTGTGCAGAGAGCCTGGTT & & & \\
\hline \multirow[t]{2}{*}{ GCLM } & Forward: ACAATACAACGGTTCAGGTGAGT & 119 & 58 & CV868255.1 \\
\hline & Reversed: GCCTGTAAAATGTGTCATTGAGG & & & \\
\hline \multirow[t]{2}{*}{$N F E 2 L 2$} & Forward: GAAAGCCCAGTCTTCATTGC & 190 & 58 & XM_005671982.1 \\
\hline & Reversed: TTGGAACCGTGCTAGTCTCA & & & \\
\hline
\end{tabular}

PCR, polymerase chain reaction; NFE2L2-ARE, nuclear factor, erythroid 2-like 2-antioxidant response element; GPX1, glutathione peroxidase1; GCLC, glutamate cysteine ligase catalytic subunit; GCLM, glutamate cysteine ligase modifier subunit. 
expression was calculated using the $2^{-\Delta \Delta \mathrm{Ct}}$ method with pooled cDNA from all samples as a reference (Livak and Schmittgen, 2001).

\section{Statistical analysis}

All data were analyzed by using the general linear model procedures of SPSS (version 16.0, SPSS Inc., Chicago, IL, USA). The four treatment groups were analyzed as a $2 \times 2$ factorial arrangement to elucidate the main effects of FA, VE and their interactions. The results were presented by mean values and the standard error of the mean. When the interaction was significant, differences among means were determined using the least significant difference test. The $\mathrm{p}<0.05$ was considered significant, whereas $\mathrm{p}<0.10$ was considered a trend. All data were analyzed with individual pig as the experimental unit $(\mathrm{n}=$ $6)$.

\section{RESULTS}

\section{Carcass traits and meat quality}

As shown in Table 3, no FA effects on back fat depth, lean percentage, and loin eye area were observed. However, loin eye area of pigs fed the VE-supplemented diets were greater $\left(43.50 \mathrm{~cm}^{2}\right.$ vs $\left.37.64 \mathrm{~cm}^{2} ; \mathrm{p}<0.05\right)$ than pigs fed the diets without VE-supplemented. There were no significant differences of $\mathrm{pH}_{\mathrm{u}}, \mathrm{L}^{*}, \mathrm{~b}^{*}$, or drip loss of LD muscle in all of treatments. However, pigs fed FA-supplemented diets increased $\mathrm{pH}_{45 \min }$ value $(6.25$ vs $6.08 ; \mathrm{p}<0.05)$ compared with pigs fed diets without FA-supplemented. In addition, supplementation with FA reduced $(\mathrm{p}<0.05)$ shear force as pigs fed diets without VE, whereas, this change was not the case for pigs fed diets with VE supplementation
(Interaction; $\mathrm{p}<0.05$ ). The similar variation was also observed in the VE treatment, supplementation with VE individually reduced $(\mathrm{p}<0.05)$ shear force.

\section{Hepatic and sarcous antioxidative parameters}

In this study, no significant VExFA interaction effect on oxidative stability of liver was found (Table 4). Whereas, pigs fed VE-supplemented diets decreased the content of MDA $(0.46 \mathrm{mg} / \mathrm{g}$ of protein vs $1.51 \mathrm{mg} / \mathrm{g}$ of protein; $\mathrm{p}<$ $0.05)$, increased the activity of GSH-Px $(84.69 \mathrm{U} / \mathrm{mg}$ of protein vs $64.29 \mathrm{U} / \mathrm{mg}$ of protein; $\mathrm{p}<0.05)$ and the content of GSH $(10.64 \mathrm{mg} / \mathrm{g}$ of protein vs $8.27 \mathrm{mg} / \mathrm{g}$ of protein; $\mathrm{p}<0.05)$ compared with pigs fed diets without VEsupplemented. Except for increasing the activity of GSH-Px (83.00 U/mg of protein vs $65.99 \mathrm{U} / \mathrm{mg}$ of protein; $\mathrm{p}<0.05)$ in liver, dietary FA supplementation did not affect the other antioxidative parameters.

In LD muscle, pigs fed VE-supplemented diets decreased the content of MDA $(0.059 \mathrm{mg} / \mathrm{g}$ of protein vs. $0.091 \mathrm{mg} / \mathrm{g}$ of protein; $\mathrm{p}<0.05)$ and increased the activity of GSH-Px $(8.47 \mathrm{U} / \mathrm{mg}$ of protein vs $6.47 \mathrm{U} / \mathrm{mg}$ of protein; $\mathrm{p}<0.05)$ compared with pigs fed diets without VEsupplemented. Pigs fed FA-supplemented diets decreased the content of MDA $(0.059 \mathrm{mg} / \mathrm{g}$ of protein vs $0.091 \mathrm{mg} / \mathrm{g}$ of protein; $\mathrm{p}<0.05)$ compared with pigs fed diets without FA-supplemented.

\section{mRNA expression}

Dietary VE or FA supplementation did not affect the mRNA expressions of genes related to the NFE2L2-ARE pathway in either liver or LD muscles (Table 5).

Table 3. Effect of dietary supplementation with vitamin E (VE) and ferulic acid (FA) on carcass traits and meat quality of finishing pigs $(\mathrm{n}=6)$

\begin{tabular}{|c|c|c|c|c|c|c|c|c|}
\hline \multirow{3}{*}{ Items } & \multicolumn{4}{|c|}{ Treatment $^{1}$} & \multirow{3}{*}{ SEM } & \multirow{2}{*}{\multicolumn{3}{|c|}{ Significance (p-value) }} \\
\hline & \multicolumn{2}{|c|}{0} & \multicolumn{2}{|c|}{400} & & & & \\
\hline & 0 & 100 & 0 & 100 & & VE & FA & $\mathrm{VE} \times \mathrm{FA}^{2}$ \\
\hline Back fat (cm) & 2.88 & 2.79 & 2.54 & 2.71 & 0.08 & 0.198 & 0.824 & 0.415 \\
\hline Lean percentage $(\%)$ & 57.58 & 57.68 & 57.57 & 57.40 & 0.07 & 0.295 & 0.765 & 0.324 \\
\hline Loin eye area $\left(\mathrm{cm}^{2}\right)$ & 37.17 & 38.10 & 42.30 & 44.70 & 0.98 & 0.001 & 0.282 & 0.631 \\
\hline $\mathrm{pH}_{45 \min }$ & 6.07 & 6.21 & 6.09 & 6.28 & 0.04 & 0.554 & 0.034 & 0.721 \\
\hline $\mathrm{pH}_{\mathrm{u}}$ & 5.67 & 5.74 & 5.82 & 5.73 & 0.03 & 0.281 & 0.873 & 0.220 \\
\hline Lightness (L*) & 46.77 & 46.64 & 45.30 & 47.40 & 0.81 & 0.842 & 0.583 & 0.533 \\
\hline Redness $\left(\mathrm{a}^{*}\right)$ & 3.90 & 5.51 & 4.62 & 3.89 & 0.32 & 0.466 & 0.475 & 0.073 \\
\hline Yellowness (b*) & 11.03 & 9.68 & 9.71 & 9.71 & 0.27 & 0.269 & 0.243 & 0.243 \\
\hline Drip loss (\%) & 2.25 & 2.20 & 2.25 & 2.17 & 0.03 & 0.848 & 0.367 & 0.875 \\
\hline Shear force $(N)$ & $4.08^{\mathrm{a}}$ & $3.04^{\mathrm{b}}$ & $3.01^{\mathrm{b}}$ & $3.61^{\mathrm{ab}}$ & 0.14 & 0.214 & 0.545 & 0.002 \\
\hline
\end{tabular}

SEM, pooled standard error of the means.

${ }^{1}$ A $2 \times 2$ factorial arrangement with 2 supplemental levels of VE ( 0 or $400 \mathrm{mg} / \mathrm{kg} \alpha$-tocopheryl acetate) and 2 supplemental levels of FA ( 0 or $100 \mathrm{mg} / \mathrm{kg}$ ferulic acid) in basal diets.

${ }^{2} \mathrm{VE} \times \mathrm{FA}$, the interaction between VE and FA.

${ }^{a, b}$ Means within a row with no common superscript differ significantly $(p<0.05)$. 
Table 4. Effect of dietary supplementation with vitamin E (VE) and ferulic acid (FA) on antioxidant capacity in liver and longissimus dorsi muscle of finishing pigs $(\mathrm{n}=6)$

\begin{tabular}{|c|c|c|c|c|c|c|c|c|}
\hline \multirow{3}{*}{ Items } & \multicolumn{4}{|c|}{ Treatment $^{1}$} & \multirow{3}{*}{ SEM } & \multirow{2}{*}{\multicolumn{3}{|c|}{ Significance (p-value) }} \\
\hline & \multicolumn{2}{|c|}{0} & \multicolumn{2}{|c|}{400} & & & & \\
\hline & 0 & 100 & 0 & 100 & & VE & FA & $\mathrm{VE} \times \mathrm{FA}^{2}$ \\
\hline \multicolumn{9}{|l|}{ Liver } \\
\hline MDA (nmol/mg of protein) & 1.76 & 1.25 & 0.48 & 0.44 & 0.16 & 0.001 & 0.129 & 0.187 \\
\hline GSH-Px (U/mg of protein) & 59.32 & 69.26 & 72.65 & 96.73 & 4.52 & 0.013 & 0.032 & 0.340 \\
\hline GSH (mg/g of protein) & 7.97 & 8.56 & 11.12 & 10.16 & 0.44 & 0.004 & 0.791 & 0.274 \\
\hline \multicolumn{9}{|l|}{ Longissimus dorsi } \\
\hline MDA (nmol/mg of protein) & 0.120 & 0.061 & 0.061 & 0.057 & 0.009 & 0.048 & 0.043 & 0.079 \\
\hline GSH-Px (U/mg of protein) & 5.13 & 7.81 & 8.74 & 8.20 & 0.53 & 0.041 & 0.247 & 0.092 \\
\hline GSH (mg/g of protein) & 3.13 & 3.43 & 3.23 & 3.58 & 0.09 & 0.481 & 0.071 & 0.885 \\
\hline
\end{tabular}

SEM, pooled standard error of the means; MDA, malondialdehyde; GSH-Px, glutathione peroxidase; GSH, glutathione.

${ }^{1}$ A $2 \times 2$ factorial arrangement with 2 supplemental levels of VE ( 0 or $400 \mathrm{mg} / \mathrm{kg} \alpha$-tocopheryl acetate) and 2 supplemental levels of FA ( 0 or $100 \mathrm{mg} / \mathrm{kg}$ ferulic acid) in basal diets.

${ }^{2}$ VExFA, the interaction between VE and FA.

\section{DISCUSSION}

In inconsistent with previous reports (Hasty et la., 2002; Guo et al., 2006), the data of the present study found that dietary supplementation with VE increased loin eye area. These paradoxical results may be due to the different levels of dietary VE. In the previous studies by Hasty et al. (2002) and Guo et al., the levels of VE supplementation were 351 $\mathrm{IU} / \mathrm{kg}(258 \mathrm{mg} / \mathrm{kg})$ and $400 \mathrm{IU} / \mathrm{kg}(294 \mathrm{mg} / \mathrm{kg})$, respectively. So, we had chosen $400 \mathrm{mg} / \mathrm{kg}$ as the VE supplementary level in this study. Thus, we speculated that higher levels of dietary VE may contribute to improve loin eye area, but the exact mechanism was not clear. Therefore, further studies are needed to clarify its mechanism.

In the present study, higher $\mathrm{pH}_{45 \min }$ value was observed in the pigs fed FA-supplemented diets, whereas, VE treatment had no effect on $\mathrm{pH}_{45 \min }$ value. It is well known that glycolytic potential (GP) is a core factor to influence postmortem muscle $\mathrm{pH}$ value. Higher pre-slaughter muscle glycogen content resulted in rapid $\mathrm{pH}$ decline postmortem and low ultimate $\mathrm{pH}$ by increased GP (Monin and Sellier, 1985). In addition, previous studies showed that antioxidant could decrease leakage of $\mathrm{Ca}^{2+}$ from the mitochondria and sarcoplasmic reticulum into the sarcoplasm by enhance the stability of membrane, then reduced GP and increased $\mathrm{pH}$ value (den Hertog-Meischke et al., 1997). Whereas, VE could inhibit protein kinase $\mathrm{C}$ and then increase the activity of glycogen synthase (Rosenvold et al., 2002), therefore the VE-induced synthesis of glycogen may counterbalance the benefit of VE-induced reduction of GP. Thus dietary supplementation with VE may have no effect on $\mathrm{pH}$ value, which could prove our results about VE treatment. Given

Table 5. Effect of dietary supplementation with vitamin E (VE) and ferulic acid (FA) on the mRNA expressions of NFE2L2-ARE related genes in liver and longissimus dorsi muscle of finishing pigs $(\mathrm{n}=6)$

\begin{tabular}{|c|c|c|c|c|c|c|c|c|}
\hline \multirow{3}{*}{ Items } & \multicolumn{4}{|c|}{ Treatment $^{1}$} & \multirow{3}{*}{ SEM } & \multirow{2}{*}{\multicolumn{3}{|c|}{ Significance (p-value) }} \\
\hline & \multicolumn{2}{|c|}{0} & \multicolumn{2}{|c|}{400} & & & & \\
\hline & 0 & 100 & 0 & 100 & & VE & FA & $\mathrm{VE} \times \mathrm{FA}^{2}$ \\
\hline \multicolumn{9}{|l|}{ Liver } \\
\hline$G P X 1$ & 0.91 & 1.14 & 1.11 & 1.57 & 0.11 & 0.127 & 0.100 & 0.555 \\
\hline$G C L C$ & 2.00 & 2.80 & 2.80 & 4.01 & 0.30 & 0.095 & 0.096 & 0.718 \\
\hline GCLM & 1.19 & 0.85 & 0.88 & 1.17 & 0.10 & 0.984 & 0.904 & 0.149 \\
\hline NFE2L2 & 1.67 & 1.95 & 1.62 & 2.30 & 0.25 & 0.782 & 0.377 & 0.703 \\
\hline \multicolumn{9}{|c|}{ Longissimus dorsi } \\
\hline$G P X 1$ & 2.00 & 2.51 & 1.89 & 1.62 & 0.24 & 0.326 & 0.809 & 0.441 \\
\hline$G C L C$ & 0.84 & 0.77 & 0.52 & 0.72 & 0.09 & 0.316 & 0.704 & 0.471 \\
\hline GCLM & 3.16 & 4.12 & 3.41 & 3.83 & 0.45 & 0.985 & 0.482 & 0.781 \\
\hline NFE2L2 & 3.40 & 4.60 & 3.64 & 3.61 & 0.31 & 0.566 & 0.371 & 0.347 \\
\hline
\end{tabular}

SEM, pooled standard error of the means; NFE2L2-ARE, nuclear factor, erythroid 2-like 2-antioxidant response element; GPX1, glutathione peroxidase 1; $G C L C$, glutamate cysteine ligase catalytic subunit; GCLM, glutamate cysteine ligase modifier subunit.

${ }^{1}$ A $2 \times 2$ factorial arrangement with 2 supplemental levels of VE $(0$ or $400 \mathrm{mg} / \mathrm{kg} \alpha$-tocopheryl acetate $)$ and 2 supplemental levels of FA ( 0 or $100 \mathrm{mg} / \mathrm{kg}$ ferulic acid) in basal diets.

${ }^{2} \mathrm{VE} \times \mathrm{FA}$, the interaction between VE and FA. 
there was no report regarding the disadvantage of FA on glycogen synthesis, we speculated that FA as an antioxidant could contribute to high $\mathrm{pH}$ value.

As shown in Table 3, the VExFA interaction significantly affect shear force of LD muscle, which seems to be associated with the observed interaction for MDA in LD muscle (Table 4). It is well known that MDA is a main indicator of endogenous lipid peroxidation (Ma et al., 2010a) and represents the oxidative degree of muscle to some extent. Moreover, Rowe et al. (2004) reported that muscle oxidation could decrease meat tenderness by inhibiting the activities of protein catabolic enzyme and other proteolytic enzymes in muscle. Apparently, in this study, FA or VE added in individually reduced the MDA production in muscle, whereas the combined addition of FA and VE showed negative synergistic effects in inhibiting MDA production. Similar effects were also observed during dietary treatment on shear force of muscle. These results may illustrate that antagonistic interactions were resided in the compound of FA and VE. In addition, Trombino et al. (2004) found that during 2, 2'-azobis (2-amidinopropane) (AAPH)-induced MDA formation in rat liver microsomal membranes, the combined inhibitions of FA and $\alpha$ tocopherol were lower than the sum of the inhibitions obtained individually by the two antioxidants. They explained the negative synergistic interactions between FA and $\alpha$-tocopherol lied in that $\alpha$-tocopherol enhanced the AAPH-induced loss of FA in the presence of $\alpha$-tocopherol.

In our study, the VE-induced reductions of MDA in liver and muscle were in agreement with the VE research on pigs (Meineri et al., 2013), which has reported that VE supplementation $(0.5 \mathrm{~g} / \mathrm{kg}$ diet $)$ decreased MDA in pork. $\mathrm{VE}$ is a highly effective liposoluble chain-breaking antioxidant that preventing lipid peroxidation (Diplock, 1978). In addition, the presence of the VE in animal tissue only can be accepted by dietary supplementation, and Meineri et al. (2013) concluded that dietary supplementation with supra-nutritional levels of $\alpha$ tocopherol was an efficient way of improving the pork quality. As well as, lower sarcous MDA concentration caused by dietary FA supplementation was observed in the present study. Similarly, treatment with FA $(40 \mathrm{mg} / \mathrm{kg}$ or 80 $\mathrm{mg} / \mathrm{kg}$ diet) decreased the Carbon tetrachloride-induced formation of MDA in liver of mice (Kim et al., 2011). However, there is little literature concerning the effect of dietary FA supplementation on MDA content in pork. This illustrates that both VE and FA as antioxidant could improve resistance to oxidation as measured by decreased MDA content in liver and muscle.

A previous study suggested that diet with abundant natural antioxidants (vitamins), contributes to higher activities of antioxidant enzymes, and delays lipid oxidation in fresh and storage meat (Descalzo and Sancho, 2008). Of the antioxidant system, GSH-Px is the key peroxideremoving enzymes located in the cytosol since it reduces a number of peroxides (Chan et al., 1994). In the present study, dietary supplementation with VE improved the activities of GSH-Px in liver and LD muscle. In agreement with our results, O'Grady et al. (2001) reported that dietary supplementation with $300 \mathrm{IU} / \mathrm{kg}$ of DL- $\alpha$-tocopheryl acetate for 55 day pre-slaughter resulted in improvement in GSHPx activity in beef. Additionally, Zhang et al. (2012a) concluded that the improvement of GSH-Px activity in chicken was due to $30 \mathrm{mg} / \mathrm{kg}$ and $60 \mathrm{mg} / \mathrm{kg}$ of dietary RRR$\alpha$-tocopherol succinate diet supplementation. On the contrary, Lauridsen et al. (1999) found that dietary supplementation with DL- $\alpha$-tocopheryl acetate did not significantly influence GSH-Px activity in muscles of pigs. The difference among the VE-induced variation of GSH-PX activity in muscle may be due to the disparate animals and VE addition levels in these experiments. Additionally, Son et al. (2010) showed that, the activity of GSH-Px in liver of mice fed the FA-supplemented high fat diet was increased than mice fed the high fat diet without FA-supplemented. Balasubashini et al. (2004) reported supplementation with FA to the diabetic rats resulted in increased activity of GSHPx in liver. In agreement with those findings, our results showed that dietary supplementation with FA could increase GSH-Px activity in liver of pigs.

It is generally accepted that GSH is an important redox buffer within cells. Reduction of GSH could spontaneously converse to oxidized GSH (GSSG) or by enzymatic catalysis to trap radical species (Ghezzi, 2005). In our study, dietary supplementation with VE increased GSH content in liver of pigs, which was comparable to the study of Ozkan et al. (2007), who reported that dietary supplementation with VE resulted in higher GSH content in livers of broilers and rats. However, Cadenas et al. (1995) suggested that dietary VE treatment did not affect the GSH concentration in liver of guinea pigs. In the present study, dietary supplementation with FA tended to improve the content of GSH in LD muscles. In agreement with the findings of Ma et al. (2010b), FA evidently increased the intracellular GSH levels in radiated human umbilical vein endothelial cells. In addition, the same in vivo results have been reported in diabetic rats supplementation with FA (Balasubashini et al., 2004).

Cytosolic glutathione peroxidase $(G P X l)$ as the major antioxidant selenoprotein, could use GSH as its substrate and oxidize GSH to GSSG, convert hydrogen peroxide to water and lipid peroxides to their respective alcohols ( $\mathrm{Li}$ et al., 2007). Gamma-glutamyl cysteine synthetase, also known as glutamate cysteine ligase $(G C L)$, catalyzes the rate-limiting step in GSH biosynthesis, and is a heterodimer composed of the larger catalytic subunit (GCLC) and smaller modulator subunit (GCLM) (Zhang et al., 2012b). It 
is well known that GPX1, GCLC and GCLM were downstream target genes of NFE2L2-ARE which were the key regulators involved in cellular antioxidant response to ROS (Kensler et al., 2007). Some previous studies reported that VE and FA, besides their direct antioxidant function, may also exert an indirect antioxidant activity by enhancing the cell's antioxidant system through activate the antioxidant enzymes that are related to NFE2L2 (Ma et al., 2010b; Li et al., 2012). Thus, the mRNA levels of genes related to the NFE2L2-ARE pathway in liver and LD muscles were measured in the present study. Our findings indicated that no significant differences of the mRNA expressions of GPX1, GCLC, GCLM and NFE2L2 genes were observed in liver and LD muscle among treatments. It is generally considered that that the expression of NFE2L2 mRNA is broad and independent of inducers, and exhibited a post-transcriptional mechanism(s) for NFE2L2 activation (Ma, 2013). This theory could support our results that dietary supplementation with VE or FA did not affect the mRNA expression of NFE2L2. In contrast, Feng et al. (2010) studied that $\alpha$-tocopherol treatment increased the expressions and/or activities of the Phase II enzymes by activated the KEAP1/NFE2L2 pathway in human retinal pigment epithelial cell which exposed to acrolein. Regarding to FA, Ma et al. (2010b) suggested that FAinduced NFE2L2 activation play an important role in protecting human umbilical vein endothelial cells from radiation induced oxidative stress by increasing the transcription of antioxidant related genes. The different results for VE or FA treatment induced NFE2L2 activation may be due to that the subjects in those studies of Feng et al. (2010) and Ma et al. (2010b) were cells in oxidative stress model. Whereas, the subjects in our study were pigs under the normal conditions of farming, without pre-oxidative stress treatment, dietary FA or VE supplementation on appropriate level may not easily change the genes expressions related to NFE2L2.

\section{CONCLUSION}

Dietary supplementation with FA and VE can improve pork quality at a certain degree. This improvement is achieved through the reduction of MDA, elevation activity of GSH-Px and content of GSH induced by the antioxidant activity of FA and VE, but not by activating NFE2L2 pathway under the normal conditions of farming. However, as the results showed that FA or VE added in individually may be better than combined addition for the improvement of pork quality.

\section{ACKNOWLEDGMENTS}

This study was supported by the Fundamental Research
Funds for the Central Universities of China (KYZ201004 and KYZ201222), the National Science \& Technology Pillar Program during the Twelfth Five-year Plan Period of China (2012BAD28B03) and the Three Agricultural Projects of Jiangsu province of China (SX(2011)146).

\section{REFERENCES}

Balasubashini, M. S., R. Rukkumani, and V. P. Menon. 2003. Protective effects of ferulic acid on hyperlipidemic diabetic rats. Acta Diabetol. 40:118-122.

Balasubashini, M. S., R. Rukkumani, P. Viswanathan, and V. P. Menon. 2004. Ferulic acid alleviates lipid peroxidation in diabetic rats. Phytother. Res. 18:310-314.

Cadenas, S., C. Rojas, R. Perez-Campo, M. Lopez-Torres, and G. Barja. 1995. Vitamin E protects guinea pig liver from lipid peroxidation without depressing levels of antioxidants. Int. J. Biochem. Cell Biol. 27:1175-1181.

Chan, K. M., E. A. Decker, and C. Feustman. 1994. Endogenous skeletal muscle antioxidants. Crit. Rev. Food. Sci. Nutr. 34:403-426.

Copple, I. M., C. E. Goldring, N. R. Kitteringham, and B. K. Park. 2008. The Nrf2-Keap1 defence pathway: Role in protection against drug-induced toxicity. Toxicology 246:24-33.

Corino, C., S. Magni, G. Pastorelli, R. Rossi, and J. Mourot. 2003. Effect of conjugated linoleic acid on meat quality, lipid metabolism, and sensory characteristics of dry-cured hams from heavy pigs. J. Anim. Sci. 81:2219-2229.

den Hertog-Meischke, M. J., F. J. Smulders, J. H. Houben, and G. Eikelenboom. 1997. The effect of dietary vitamin E supplementation on drip loss of bovine longissimus lumborum, psoas major and semitendinosus muscles. Meat Sci. 45:153160.

Descalzo, A. M. and A. M. Sancho. 2008. A review of natural antioxidants and their effects on oxidative status, odor and quality of fresh beef produced in Argentina. Meat Sci. 79: 423436.

DeVol, D. L., F. K. McKeith, P. J. Bechtel, J. Novakofski, R. D. Shanks, and T. R. Carr. 1988. Variation in composition and palatability traits and relationships between muscle characteristics and palatability in a random sample of pork carcasses. J. Anim. Sci. 66:385-395.

Diplock, A. T. 1978. The biological function of vitamin E and the nature of the interaction of the vitamin with selenium. World Rev. Nutr. Diet 31:178-183.

Fang, Y. Z., S. Yang, and G. Wu. 2002. Free radicals, antioxidants, and nutrition. Nutrition 18:872-879.

Feng, Z., Z. Liu, X. Li, H. Jia, L. Sun, C. Tian, L. Jia, and J. Liu. 2010. Alpha-tocopherol is an effective phase II enzyme inducer: protective effects on acrolein-induced oxidative stress and mitochondrial dysfunction in human retinal pigment epithelial cells. J. Nutr. Biochem. 21:1222-1231.

Ghezzi, P. 2005. Regulation of protein function by glutathionylation. Free Radic. Res. 39:573-580.

Guo, Q., B. T. Richert, J. R. Burgess, D. M. Webel, D. E. Orr, M. Blair, G. E. Fitzner, D. D. Hall, A. L. Grant, and D. E. Gerrard. 2006. Effects of dietary vitamin $\mathrm{E}$ and fat supplementation on pork quality. J. Anim. Sci. 84:3089-3099. 
Hasty, J. L., E. van Heugten, M. T. See, and D. K. Larick. 2002. Effect of vitamin $\mathrm{E}$ on improving fresh pork quality in berkshire- and hampshire-sired pigs. J. Anim. Sci. 80:32303237.

Honikel, K. O. 1998. Reference methods for the assessment of physical characteristics of meat. Meat Sci. 49:447-457.

Kensler, T. W., N. Wakabayashi, and S. Biswal. 2007. Cell survival responses to environmental stresses via the Keap1Nrf2-ARE pathway. Annu. Rev. Pharmacol. Toxicol. 47:89116.

Kim, H. Y., J. Park, K. H. Lee, D. U. Lee, J. H. Kwak, Y. S. Kim, and S. M. Lee. 2011. Ferulic acid protects against carbon tetrachloride-induced liver injury in mice. Toxicology 282: 104-111.

Kuhn, G., U. Hennig, C. Kalbe, C. Rehfeldt, M. Q. Ren, S. Moors, and G. H. Degen. 2004. Growth performance, carcass characteristics and bioavailability of isoflavones in pigs fed soy bean based diets. Arch. Anim. Nutr. 58:265-276.

Lauridsen, C., J. H. Nielsen, P. Henckel, and M. T. Sorensen. 1999. Antioxidative and oxidative status in muscles of pigs fed rapeseed oil, vitamin E, and copper. J. Anim. Sci. 77:105-115.

Lei, X. G., W. H. Cheng, and J. P. McClung. 2007. Metabolic regulation and function of glutathione peroxidase-1. Annu. Rev. Nutr. 27:41-61.

Li, G., M. J. Lee, A. B. Liu, Z. Yang, Y. Lin, W. J. Shih, and C. S. Yang. 2012. The antioxidant and anti-inflammatory activities of tocopherols are independent of Nrf2 in mice. Free Radic. Biol. Med. 52:1151-1158.

Li, Y., X. Tang, and F. Gao. 2006. Establishment of prediction model of the lean percentage of swine carcasses in China. Journal of Northwest Sci-Tech University of Agriculture and Forestry 34:27-31 (In Chinese).

Livak, K. J. and T. D. Schmittgen. 2001. Analysis of relative gene expression data using real-time quantitative pcr and the 2(Delta Delta C (T)) method. Methods 25:402-408.

Ma, Q. 2013. Role of Nrf2 in oxidative stress and toxicity. Annu. Rev. Pharmacol. Toxicol. 53:401-426.

Ma, X., Y. Lin, Z. Jiang, C. Zheng, G. Zhou, D. Yu, T. Cao, J. Wang, and F. Chen. 2010a. Dietary arginine supplementation enhances antioxidative capacity and improves meat quality of finishing pigs. Amino Acids 38:95-102.

Ma, Z. C., Q. Hong, Y. G. Wang, H. L. Tan, C. R. Xiao, Q. D. Liang, B. L. Zhang, and Y. Gao. 2010b. Ferulic acid protects human umbilical vein endothelial cells from radiation induced oxidative stress by phosphatidylinositol 3-kinase and extracellular signal-regulated kinase pathways. Biol. Pharm. Bull. 33:29-34.
Meineri, G., C. Medana, V. Giancotti, S. Visentin, and P. G. Peiretti. 2013. Effect of dietary supplementation of vitamin $\mathrm{E}$ in pigs to prevent the formation of carcinogenic substances in meat products. J. Food. Compost. Anal. 30:67-72.

Monin, G. and P. Sellier. 1985. Pork of low technological quality with a normal rate of muscle ph fall in the immediate postmortem period: the case of the hampshire breed. Meat Sci. 13: 49-63.

O'Grady, M. N., F. J. Monahan, R. J. Fallon, and P. Allen. 2001. Effects of dietary supplementation with vitamin $\mathrm{E}$ and organic selenium on the oxidative stability of beef. J. Anim. Sci. 79: 2827-2834.

Ozkan S, H. B. Malayoglu, S. Yalcin, F. Karadas, S. Kocturk, M. Cabuk, G. Oktay, S. Ozdemir, E. Ozdemir, and M. Ergul. 2007. Dietary vitamin E (alpha-tocopherol acetate) and selenium supplementation from different sources: performance, ascitesrelated variables and antioxidant status in broilers reared at low and optimum temperatures. Br. Poult. Sci. 48:580-593.

Rosenvold, K., H. N. Laerke, S. K. Jensen, A. H. Karlsson, K. Lundstrom, and H. J. Andersen. 2002. Manipulation of critical quality indicators and attributes in pork through vitamin $\mathrm{E}$ supplementation, muscle glycogen reducing finishing feeding and pre-slaughter stress. Meat Sci. 62:485-496.

Rowe, L. J., K. R. Maddock, S. M. Lonergan, and E. HuffLonergan. 2004. Oxidative environments decrease tenderization of beef steaks through inactivation of $\mu$-calpain. J. Anim. Sci. 82:3254-3266.

Son, M. J., C. W. Rico, S. H. Nam, and M. Y. Kang. 2010. Influence of oryzanol and ferulic acid on the lipid metabolism and antioxidative status in high fat-fed mice. J. Clin. Biochem. Nutr. 46:150-156.

Srinivasan, M., A. R. Sudheer, and V. P. Menon. 2007. Ferulic acid: therapeutic potential through its antioxidant property. J. Clin. Biochem. Nutr. 40:92-100.

Trombino, S., S. Serini, F. Di Nicuolo, L. Celleno, S. Ando, N. Picci, G. Calviello, and P. Palozza. 2004. Antioxidant effect of ferulic acid in isolated membranes and intact cells: Synergistic interactions with alpha-tocopherol, beta-carotene, and ascorbic acid. J. Agric. Food Chem. 52:2411-2420.

Zhang, H., P. Limphong, J. Pieper, Q. Liu, C. K. Rodesch, E. Christians, and I. J. Benjamin. 2012b. Glutathione-dependent reductive stress triggers mitochondrial oxidation and cytotoxicity. FASEB J. 26:1442-1451.

Zhang, X., G. Wang, Y. Zhou, and T. Wang. 2012a. Effect of RRR$\alpha$-tocopherol succinate on the meat quality and antioxidative status in broilers. S. Afr. J. Anim. Sci. 42:341-353. 